\title{
Active management of third stage of labour: comparison between prophylactic intramuscular methylergometrine and intramuscular oxytocin
}

\author{
Shilu Adhikari, Ashma Rana, Kesang D Bista \\ Department of Obstetrics and Gynecology, TUTH
}

\begin{abstract}
Aim: Aimed at comparing the efficacy of prophylactic intramuscular methylergometrine with intramuscular oxytocin in reducing blood loss in the third stage of labour (TSL).

Methods: This is a randomized, comparative, clinical trial to compare the efficacy of intramuscular methylergometrine with intramuscular oxytocin in the third stage of labour for the prevention of postpartum hemorrhage Two hundred women undergoing normal vaginal delivery were recruited, 100 in each groupGroup A receiving $.2 \mathrm{mg}$ methylergometrine intramuscularly and Group B receiving $10 U$ oxytocin intramuscularly immediately after the delivery of the anterior shoulder of the baby. The efficacy and the safety of these two drugs were analyzed on the basis of percentages fall in haemoglobin $(\mathrm{Hb})$ and haematocrit (Hct) level from before delivery to 24 completed hours after delivery, need for additional uterotonic agents, need for exploration and uterine evacuation, need for blood transfusion, duration of third stage of labour and the numbers of retained placenta and need for MRP.
\end{abstract}

Results: Intramuscular methylergometrine was observed to be equally effective as intramuscular oxytocin in prevention of post partum haemorrhage (PPH) [defined as fall in $\mathrm{Hb}$ and /or $\mathrm{Hct}_{\mathrm{c}}$ level ${ }^{3} 10 \%$ from before delivery to 24 hours after delivery]. There was no difference in the risk of prolonged third stage, need for additional uterotonic agents, need for exploration and uterine evacuation and need for blood transfusion in the two groups. The side effects were all mild in nature and the overall incidence was too low for statistical significance to be elicited.

Conclusion: Intramuscular methylergometrine is as efficacious as intramuscular oxytocin in the prevention of third stage blood loss with comparable side effects.

Keywords: Third stage of labour, postpartum hemorrhage, methylergometrine, oxytocin.

\section{Introduction}

Active management of labour was introduced in 1963 at the National Maternity Hospital in Dublin ${ }^{1}$. A component of this package constitutes administration of prophylactic uterotonic within one minute of the delivery of the baby, immediate delivery of the placenta by controlled cord traction and uterine massage which shortens the duration of third stage of labour reducing the bloodloss.

For this reason, most countries across the world now have adopted this principle to reduce Primary PPH, defined as bleeding in excess of $500 \mathrm{ml}$ in the first 24 hours following delivery (WHO 1990). ${ }^{2}$ This quantitative definition of $\mathrm{PPH}$, estimating blood loss is subjective and grossly inaccurate hence has been better proposed by American College of Obstetrics and Gynecology 2001 that PPH should be labeled by per partum fall in hemoglobin and/or hematocrit level by $10 \%$ from before to 24 hours after delivery. ${ }^{3}$ Many authors also accepted this criterion. ${ }^{4-7}$

WHO estimates that nearly 51,500 women across the world die every year mostly from $\mathrm{PPH} .{ }^{8} \mathrm{PPH}$ is the major direct cause of maternal mortality, accounting for $46.3 \%$ of all deaths (Nepal Family Health Survey 1996). Therefore prevention of PPH by administration of

Correspondence

Dr. Shilu Adhikari, MD

Dept. of Obstetrics and Gynaecology, TU Teaching Hospital.

Email: adhikarishilu@gmail.com 
prophylactic uterotonics, like ergometrine, oxytocin, a combination of both ergometrine and oxytocin or prostaglandin, have been used in active management of the third stage of labour (AMTSL). The particular choice of one of them is not known.

Until five years ago, methylergometrine ( $2 \mathrm{mg}$ ) intramuscularly was used and is currently replaced by oxytocin (10U) intramuscularly. Either due to the drug or because of other factors, the current observation is an increase in the incidence of PPH [in 3 months period in 2056 B.S. from $1^{\text {st }}$ Kartik- $1^{\text {st }}$ Magh $\left(15^{\text {th }}\right.$ Oct $-14^{\text {th }}$ Jan 1998/99)] when methylergometrine was used as third stage prophylaxis, was $2.41 \%$ against 3 the same months in 2060 B.S. (2003/04). When the intramuscular oxytocin was used AMTSL, the incidence of PPH was $6.21 \%$ (PPH defined as a visually estimated blood loss of more than $500 \mathrm{ml}$ during delivery). (Unpublished data)

Based on this framework the present study is aimed at comparing the efficacy of prophylactic intramuscular methylergometrine with intramuscular oxytocin in reducing blood loss in the third stage of labour (TSL).

\section{Methods}

This was a randomized, comparative, clinical trial conducted at the Maternity Unit in the Dept of Obstetrics and Gynaecology, Tribhuvan University Teaching Hospital from Falgun $1^{\text {st }} 2060$ to Magh $30^{\text {th }}$ $2061\left(13^{\text {th }}\right.$ February to $16^{\text {th }}$ January 2004$)$. During the one year study period, 2342 women delivered at TUTH, out of them 1653(70.5\%) had normal vaginal delivery. Among them 215 women (13\%) were enrolled in the study. The adequacy of sample was ensured by enrolling $>10 \%$ of the population (women having normal vaginal delivery). Later 15 of them were excluded because of instrumental delivery (3), caesarean (3) precipitated lab our (1) and failed to have their postpartum blood sample taken for repeat $\mathrm{Hb} / \mathrm{Hct}$ estimation (8) Finally 200 women, 100 in each group Group A (.2mg intramuscular methylergometrine) and Group B (10U intramuscular oxytocin) were studied.

All women with parity of $<5$, having singleton live pregnancy at or above 37 weeks of gestation, in cephalic presentation, undergoing spontaneous onset of labour and spontaneous vaginal delivery without any complicating factors were included in the study.

\section{Procedures}

Informed consent was taken for collection of blood sample for initial $\mathrm{Hb}$ and Hct estimation. Then the women were allotted consecutively into two groups at the second stage of labour when delivery was imminent i.e. if the first woman was enrolled into Group A then next would be in Group B or so on.
Deliveries were conducted in lithotomy or dorsal position. Allocated drug was administered immediately after the delivery of the baby. Early clamping of the umbilical cord and controlled cord traction were exercised by Brandt Andrew's method in all women without waiting for the signs of placental separation. If the placenta failed to deliver within 30 minutes following birth of the baby, retained placenta was diagnosed which called for manual removal. Uterine massage was done for about $10-15$ minutes after expulsion of the placenta until the uterus became well contracted. Then women were taught to massage her uterus every 15 minutes for 2 hours after delivery. All placentae were examined to rule out retained bits of placenta and membranes. Episiotomy wound, tears and lacerations if present was immediately repaired. Any haemorrhage that occurred was managed accordingly to the mandate.

After one hour of observation in the labour room for any drug side effects or additional bleeding, they were transferred to the ward respectively extending observation further for the next 24 hours for occurrence of delayed hemorrhage, additional requirement of uterotonics, blood transfusion or uterine exploration. After which, a second blood sample was collected for repeat $\mathrm{Hb}$ and $\mathrm{Hct}$ and the changes in $\mathrm{Hb} / \mathrm{Hct}$ level from the first taken at active stage of labour and second 24 hours of delivery was estimated at our own hematology, in the same computerized machine within 6 hours of collection thus calculating the percentage of fall in their values.

After the primary data collection, daily entries of these data were put in the master chart. Analysis was done with the help of a computer using Chi-square $\left({ }^{\mathrm{x} 2}\right)$ test and student's T-test. A P value of $<0.05$ was regarded as statistically significant. The computer programme used was SPSS version 11.5.

\section{Results}

The two groups were balanced at randomization for potential confounding factors viz. age, parity, booking status and gestational age at delivery. The two groups were also comparable with regard to baseline prognostic labour characteristics like duration of labour, mode of delivery, mean birth weight of the baby and the mean placental weight. The duration of third stage of labour in methylergometrine group was also not statistically different to that of oxytocin group.

There was no statistical difference in the mean fall in $\mathrm{Hb}$ and $\mathrm{Hct}$ in between methylergometrine and oxytocin groups ( $\mathrm{p}$ value $=0.56$ and 0.99 respectively). (Table1). The incidence of PPH (peripartum fall in $\mathrm{Hb}$ of ${ }^{3} 10 \%$ ) was not statistically significant in women receiving methylergometrine and women receiving oxytocin although numerically more women in intramuscular oxytocin group had a peripartum fall in $\mathrm{Hb}$ of $10 \%(34$ versus 27 ; RR $1.44,95 \%$ CI 0.94-2.21). 
Compared to women receiving methylergometrine the number of women having PPH (a peripartum fall in Hct level of $10 \%$ from before to after delivery) was more in intramuscular oxytocin group (36 versus 29). But this failed to reach statistical significance. (Table1)

To compare the efficacy of methylergometrine and oxytocin, additional parameters were assessed. These were need for additional uterotonics, need for exploration and uterine evacuation and need for blood transfusion (Table2).

Additional uterotonics was administered in four women receiving methylergometrine and five women receiving oxytocin and this was not statistically significant although oxytocin was associated with 1.25 times risk of requiring a supplementary uterotonics compared to methylergometrine (RR 1.25, 95\% CI 0.35- 4.52).

Similarly the occurrence of excessive vaginal bleeding following delivery of the baby necessitating exploration and evacuation of uterine cavity in the two groups was of no statistical significance. Three women in methylergometrine group and one in oxytocin group had exploration and uterine evacuation.

The total number of blood transfusions was too small for meaningful group differences to be elicited. Blood transfusion was given to one woman in methylergometrine group and two women in oxytocin group.

Regarding assessment of the side effects the overall incidence was extremely low and the difference between the groups was not statistically significant. Table 3. Two women receiving methylergometrine experienced nausea but none of the women in oxytocin group complained of nausea. Vomiting was seen in one woman in each group.

Tablel. Assessment of $\mathrm{Hb}$ and Hct level
Women having headache in methylergometrine and oxytocin group were 4 and 2 . None of the women in the study population in either groups complained of chest pain. The frequency of manual removal of placenta was higher in the methylergometrine group than in oxytocin group, though the difference did not reach statistical significance. Two women receiving methylergometrine and one woman receiving oxytocin had retained placenta. Manual removal of placenta (MRP) had to be performed in this particular woman in methylergometrine and none in oxytocin group. The other retained placentas expelled after bladder catheterization, additional uterotonics and uterine massage and MRP were not required.

An increase in systolic blood pressure by more than $15 \mathrm{mmHg}$ and diastolic by more than $10 \mathrm{mmHg}$ was considered as a rise in blood pressure. A rise in SBP by $15-25 \mathrm{mmHg}$ and DBP by $10-20 \mathrm{mmHg}$ was considered a mild rise in blood pressure. Severe rise in blood pressure was regarded as rise in SBP by $>25 \mathrm{mmHg}$ and DBP by $>20 \mathrm{mmHg}$. Rise in blood pressure was seen in five women in methylergometrine group ( 2 mild and 3 severe) compared to two women in oxytocin group (1 mild and 1 severe). This was of no statistical significance.

\section{Discussion}

In the present study the overall incidence of PPH using the $\mathrm{Hb}$ criteria was $35 \%$ and the incidence of major PPH was $8.67 \%$ and taking the Hct criteria PPH occurred in $40.33 \%$ and major PPH in $3.67 \%$ of women. This observation tallies with the findings from other studies conducted in a similar population..$^{6,9,10}$ Choy et al, ${ }^{6}$ reported that the drop in the $\mathrm{Hb}$ level by more than $10 \%$ was observed in about $40 \%$ and more than $20 \%$ fall was seen in about $13 \%$ of their patients. These incidences based on laboratory criteria are an objective

\begin{tabular}{|c|c|c|c|}
\hline Variable & $\begin{array}{c}\text { Group A } \\
\text { Methyl ergometrine } \\
(\mathrm{n}=100)\end{array}$ & $\begin{array}{c}\text { Group B } \\
\text { Oxytocin im. } \\
(\mathrm{n}=100)\end{array}$ & $\begin{array}{l}\text { Statistical significance } \\
\quad(p \text { value })\end{array}$ \\
\hline Mean fall in $\mathrm{Hb}(\mathrm{gm} \%)$ & $1.2 \pm 1$ & $1.1 \pm 0.8$ & 0.56 \\
\hline \multicolumn{4}{|l|}{$\%$ Fall in $\mathrm{Hb}$} \\
\hline$<10$ & 73 & 64 & 0.13 \\
\hline $10-20$ & 19 & 31 & \\
\hline$>20$ & 8 & 5 & \\
\hline Mean fall in Hct (\%) & $3.8 \pm 3.4$ & $3.8 \pm 3$ & 0.99 \\
\hline \multicolumn{4}{|l|}{$\%$ Fall in Hct } \\
\hline$<10$ & 71 & 66 & \\
\hline $10-20$ & 17 & 24 & 0.46 \\
\hline$>20$ & 12 & 10 & \\
\hline
\end{tabular}


Table 2. Comparison of Efficacy Using Other Parameters

\begin{tabular}{cccc}
\hline Variable & $\begin{array}{c}\text { Group A } \\
\text { Methyl ergometrine } \\
(\mathrm{n}=100)\end{array}$ & $\begin{array}{c}\text { Group B } \\
\text { Oxytocin im. } \\
(\mathrm{n}=100)\end{array}$ & $\begin{array}{c}\text { Statistical significance } \\
\text { (p value })\end{array}$ \\
\hline $\begin{array}{c}\text { Additional Uterotonics } \\
\text { Exploration and Uterine } \\
\text { evacuation }\end{array}$ & 4 & 5 & 1.0 \\
Blood Transfusion & 3 & 1 & 0.62 \\
\hline
\end{tabular}

Table 3. Side Effects of Methylergometrine and Oxytocin

\begin{tabular}{cccc}
\hline Variable & $\begin{array}{c}\text { Group A } \\
\text { Methyl ergometrine } \\
(\mathrm{n}=100)\end{array}$ & $\begin{array}{c}\text { Group B } \\
\text { Oxytocin im. } \\
(\mathrm{n}=100)\end{array}$ & $\begin{array}{c}\text { Statistical significance } \\
(\mathrm{p} \text { value })\end{array}$ \\
\hline Nausea & 2 & 0 & 0.5 \\
Vomiting & 1 & 1 & 0.68 \\
Headache & 4 & 2 & 1.0 \\
Retained placenta & 2 & 1 & $\mathbf{0 . 4 5}$ \\
Rise in BP & $\mathbf{5}$ & $\mathbf{2}$ & \\
\hline
\end{tabular}

measure of PPH unlike the clinical estimate, which has grossly understated the incidence of $\mathrm{PPH}$.

The incidence of PPH was similar in the two groups by both $\mathrm{Hb}(\mathrm{p}$ value $=0.13)$ and Hct criteria ( $\mathrm{p}$ value $=0.46)$. This is unlike the older studies, which reported that methylergometrine was better than oxytocin in preventing PPH. ${ }^{11-13}$ This could probably be because in the current study the dose of intramuscular oxytocin used was $10 \mathrm{U}$, which seems more optimal than a dose of $5 \mathrm{U}$ that was used in the other studies. Dumoulin ${ }^{13}$ clearly mentioned that during the course of his study the dose of oxytocin had to be changed from $5 \mathrm{U}$ to $10 \mathrm{U}$ because of the high incidence of PPH associated with the lower dose $(12.4 \%$ versus $8.6 \%)$. With this $10 \mathrm{U}$ dose of oxytocin it was observed to be as effective as $.2 \mathrm{mg}$ of methylergometrine.

Although the incidence of PPH in these two groups was statistically similar, numerically PPH occurred more frequently in the oxytocin group compared to methylergometrine group. The number of women who had a peripartum fall in $\mathrm{Hb}$ of $10 \%$ in oxytocin group was 34 compared to only 17 women in methylergometrine group; ( $\mathrm{p}$ value $=0.13$; $\mathrm{RR} 1.60,95 \%$ CI 0.54-4.72). Likewise the number of women having a peripartum fall in Hct of $10 \%$ was 36 in oxytocin group versus 29 in methylergometrine group; ( $p$ value $=0.46$; RR $1.2,95 \%$ CI of $0.54-2.65)$. Therefore the incidence of
$\mathrm{PPH}$ is higher in oxytocin group compared to methylergometrine group but this did not reach statistical significance. This could be because of a small sample size and had the study been conducted on a larger sample size this observation could have reached statistical significance.

Additional parameters used to compare the efficacy of the two regimes were also comparable. Regarding the side effect there were no serious adverse events in this study. All the adverse effects were mild and they subsided spontaneously and none of the women required any medications for these effects. The incidences were too small for any meaningful group differences to be elicited. This finding is similar to others who reported that the incidence of side effects with methylergometrine to be very low. ${ }^{6,14-16}$. These were studies conducted in the South- East Asia in a population similar to ours and they suggested that this could be due to racial variation of our women from those in the west where the side effects with methylergometrine was found to be significantly higher than with oxytocin. However until a more extensive research is conducted to find out the reason for this lower incidence of adverse effects in our women the cause remains elusive.

Among all the side effects analyzed in the current study the two most important ones were retained placenta and rise in blood pressure. Two women in 
methylergometrine group and one woman in oxytocin group had retained placenta. This was not statistically significant but in oxytocin group it was later expelled by conservative approach with additional uterotonics, uterine massage and bladder drainage whereas one woman out of the two in methylergometrine group needed MRP. However this again was not statistically significant.

Five women in methylergometrine group and two women in oxytocin group experienced a rise in blood pressure. This was also not statistically significant.

The present study showed that both intramuscular methylergometrine and intramuscular oxytocin were equally efficacious but numerically there was lesser number of women who had PPH in methylergometrine group. This was balanced by the fact that although the incidences of side effect was not statistically different in the 2 groups, a greater number of women in methylergometrine group experienced rise in blood pressure, retained placenta and MRP based on these observations it can thus be concluded that the current practice of using $10 \mathrm{U}$ of oxytocin intramuscularly for prophylaxis of $\mathrm{PPH}$ in the third stage of labour is appropriate and must be continued.

\section{Conclusion}

In this study comparing methylergometrine and oxytocin given with the delivery of anterior shoulder of the baby for active management of the third stage of labour, it was found that both intramuscular methylergometrine $(.2 \mathrm{mg})$ and intramuscular oxytocin $(10 \mathrm{U})$ were equally efficacious. However in the view of occurrence of fewer side effects in the oxytocin group compared to methylergometrine group, it can be concluded that intramuscular oxytocin is a more preferable prophylactic uterotonics in the active management of the third stage of labour for routine usage.

\section{References}

1. Chanrachakul BB, Herabutya Y, Panburana P. Active management of labour; is it suitable for a developing country ? Int J of Gynaecol Obstet 2001; 72:229-234.

2. American College of Obstetrician and Gynaecologists. Diagnosis and management of postpartum hemorrhage. ACOG Technical Bulletin Number 143. Int J of Gynaecol Obstet 1991; 36:159-163.

3. American College of Obstetrician and Gynaecologists Educational Bulletin 243.
Postpartum Hemorrhage. Int J of Gynaecol Obstet 2001; 61:79-86.

4. Boucher M, Nimrod CA, Tawagi GF, Meeker TA, Rennicks White RE, Varin J. Comparison of carbetocin and oxytocin for the prevention of postpartum hemorrhage following vaginal delivery: a double-blind randomized trial. J Obstet Gynaecol Can. 2004 May; 26(5): 481-8.

5. Kundodyiwa TW, Majoko F, Rusakaniko S. Misoprostol versus oxytocin in the third stage of labor. Int. J of Gynaecol Obstet 2001; 75: 235-241.

6. Choy CHY, Lau WC, Tam WH, Yuen PM. Randomized controlled trial of intramuscular syntometrin and intravenous oxytocin in management of the third stage of labour. Int $\mathrm{J}$ of Obstet Gynaecol 2002 Feb; 109: 173-177.

7. Bulgalho A, Daniel A, Faundes A, Cunha M. Misoprostol for prevention of PPH. Int $\mathrm{J}$ of Gynaecol Obstet 2001; 73:1 - 6.

8. Abou Zahr C, Wardlaw T. Maternal mortality in 2000: Estimates developed by WHO, UNICEF and UNFPA. Geneva: World Health Organization, 2000.

9. Hammar M, Bostrom K, Borgavall B. Comparison between the influences of methylergometrine and oxytocin on the incidence of retained placenta in the third stage of labour. Gynaecol Obstet Investigation 1990; 30: 91- 93.

10. Oral E, Gezer A, Cagdas A, Pakkal N. Oxytocin infusion in labor: the effect different indications and the use of different diluents on neonatal bilirubin levels. Arch Gynaecol Obstet 2003 Jan; 267(3): 117-20.

11. Niemchen U, Jarvinen PA. A comparative study of different medical treatment of the third stage of labour. Ann Chie Gynaecol Fenn 1963; 53: 424-429.

12. Docherty PW, HooperM. Choice of an oxytocic agent for routine use at delivery. J Obstet Gynaecol 1981; 2: 60.

13. Dumoulin JG.A reappraisal of the use of ergometrine. J Obstet Gynaecol 1981; 1:178- 181.

14. Ng PS, Chan ASM, Sin WK, Tang LCH, Cheung KB, Yuen PM.A multicentre randomized controlled trial of oral misoprostal and i.m. syntrometrine in the management of the third stage of labour. Hum Reprod 2001;16: 31-35.

15. Yuen PM, Chan NS, Yim SF, Chang AM. A randomized double blind comparison of syntometrine and syntocinon in the management of the third stage of labour. Br. J Obstet Gynaecol 1995; 102: 377-380.

16. Uma G, Chabra S. Effects of Active management of labour: Comparison of methyler-gonovine with Prostaglandin $\mathrm{F}_{2}$ Alpha. Obstet Gynaecol Today 1998; 9:558-560. 